\title{
Evaluation of Ceramic Matrix Composite Technology for Aircraft Turbine Engine Applications
}

\author{
Michael C. Halbig ${ }^{1}$, Martha H. Jaskowiak ${ }^{2}$, James D. Kiser ${ }^{3}$, and Dongming Zhu ${ }^{4}$ \\ NASA Glenn Research Center, Cleveland, $\mathrm{OH} 44135$
}

\begin{abstract}
The goals of the NASA Environmentally Responsible Aviation (ERA) Project are to reduce the NOx emissions, fuel burn, and noise from turbine engines. In order to help meet these goals, commercially-produced ceramic matrix composite (CMC) components and environmental barrier coatings (EBCs) are being evaluated as parts and panels. The components include a CMC combustor liner, a CMC high pressure turbine vane, and a CMC exhaust nozzle as well as advanced EBCs that are tailored to the operating conditions of the CMC combustor and vane. The $\mathrm{CMC}$ combustor (w/EBC) could provide $2700^{\circ} \mathrm{F}$ temperature capability with less component cooling requirements to allow for more efficient combustion and reductions in NOx emissions. The CMC vane (w/EBC) will also have temperature capability up to $2700^{\circ} \mathrm{F}$ and allow for reduced fuel burn. The CMC mixer nozzle will offer reduced weight and improved mixing efficiency to provide reduced fuel burn. The main objectives are to evaluate the manufacturability of the complex-shaped components and to evaluate their performance under simulated engine operating conditions. Progress in CMC component fabrication, evaluation, and testing is presented in which the goal is to advance from the proof of concept validation (TRL 3) to a system/subsystem or prototype demonstration in a relevant environment (TRL 6).
\end{abstract}

\section{Introduction}

Ceramic matrix composite (CMC) components and environmental barrier coatings (EBCs) are being evaluated in the NASA Environmentally Responsible Aviation (ERA) Project for aircraft turbine engine applications. The goal of the ERA Project is to explore and mature alternate aircraft designs and technologies which have the potential to decrease noise, emissions, and fuel burn to allow achievement of the midterm goals as described in the National Aeronautics Research \& Development Plan ${ }^{1}$. The midterm goals relate to performance improvements obtained by applying new technologies to "second generation" aircraft $(\mathrm{N}+2)$ which will enter service in 2020. The desired improvements to the system level metrics include a $42 \mathrm{~dB}$ reduction in noise (cumulative below Stage 4), a 75\% reduction in landing and take-off (LTO) NOx emissions (below CAEP 6), a 70\% reduction in cruise NOx emission (relative to 2005 best in class), and a 50\% decrease in aircraft fuel burn/energy consumption (relative to 2005 best in class).

To help meet the goals of the ERA Project, three different types of CMC components are being matured. These include a CMC combustor liner, a CMC high pressure turbine vane, and a CMC exhaust nozzle. Advanced EBCs specifically tailored to the needs of the CMC combustor and vane are also being developed. The primary objectives are to address commercial manufacturability of the complex-shaped components and to evaluate their performance under simulated engine operating conditions. Results of flat panel and component testing will be compared to ensure that material properties are not significantly reduced during scale-up of processing toward components of relevant size and shape. Major challenges to be addressed are in component fabrication, component cooling design, heat transfer characterization, test stand integration, and testing under relevant engine operating conditions.

The progress and results presented here for the CMC combustor liner, CMC vane, EBC coatings, and CMC exhaust nozzle are for the ERA Phase I effort. The ERA Project is a 6 year project within the Integrated Systems Research Program (ISRP). The goal of ISRP is to serve as a technology transition bridge between the lower TRL efforts on-going in the fundamental Aeronautics Research Mission Directorate (ARMD) Programs and higher TRL

${ }^{1}$ Materials Research Engineer, NASA Glenn Research Center, Cleveland, OH/MS 106-5, AIAA Member Grade.

${ }^{2}$ Materials Research Engineer, NASA Glenn Research Center, Cleveland, OH/MS 106-1, Non-member AIAA.

${ }^{3}$ Materials Research Engineer, NASA Glenn Research Center, Cleveland, OH/MS 106-1, Non-member AIAA.

${ }^{4}$ Materials Research Engineer, NASA Glenn Research Center, Cleveland, OH/MS 106-5, Non-member AIAA. 
needs of potential users. The Phase 1 effort (FY10-FY12) focuses on maturing promising technologies that address the system level metrics. Phase II (FY13-FY15) will down-select technologies and perform Integrated Technology Demonstrations (ITD) to bring the TRL level to 6.

\section{Component Evaluation and Development}

The tasks to evaluate the CMC combustor liner, the CMC turbine vane, and CMC exhaust nozzles were undertaken with the intent to advance the component technology readiness levels (TRLs) toward insertion into jet engine applications. The goal is to advance from the proof of concept validation (TRL 3) to a system/subsystem or prototype demonstration in a relevant environment (TRL 6). Technology maturation in this mid-range TRL regime is usually expensive because it involves the design, fabrication, and testing of: a) subelements and/or subcomponents; b) reduced-scale components; and ultimately, c) full-scale components. As the TRL increases from 3 to 6 , articles are tested under conditions ranging from laboratory environments that simulate some aspects of an operating engine environment to actual ground-based engine tests. Environmental barrier coatings are a key element for the success of the CMC combustor and vane components. Therefore a significant EBC effort is being conducted in-house at NASA GRC to develop and characterize advanced EBCs. The progress in this area is also presented.

Each of the three types of components offers significant improvements over currently used metallic components. The system level benefits of the CMC combustor liner are a $40 \%$ reduction in cruise NOx and a $60 \%$ reduction in cooling air. The system level benefit for the CMC turbine vane is a 3-6\% reduction in fuel burn. Conventional CMC exhaust nozzles for large commercial aircraft offer a $20+\%$ reduction in component weight. CMC mixer nozzles for regional jets and business jets offer increased mixing efficiency through improved shape retention at operating temperatures. Reduced fuel burn is the result in both cases.

The CMC components of interest are based on current state-of-the-art composite systems that are available commercially. For the combustor and vane tasks, the composite system being utilized is silicon carbide ( $\mathrm{SiC})$ fiber reinforced silicon carbide matrix composite $(\mathrm{SiC} / \mathrm{SiC})$. With current commercial processing methods and the use of Hi-Nicalon Type-S fiber, the components could have temperature capability up to $2400^{\circ} \mathrm{F}$. Through the use of advanced EBCs that also perform as thermal barrier coatings (TBCs), the vane and liner components could have surface temperature capability to $2700^{\circ} \mathrm{F}$. The EBCs also provide reduced erosion rates to enhance durability and prolong component life. For the CMC exhaust nozzles, the composite system of choice is an oxide fiber reinforced oxide matrix composite (oxide/oxide) that could operate at $1500^{\circ} \mathrm{F}$ for thousands of hours. The material system does not require a protective coating to prevent oxidation, due to the use of oxide constituents.

\section{A. CMC Combustor}

As a combustor liner material, $\mathrm{SiC} / \mathrm{SiC}$ composites are an enabling material that can help meet the $\mathrm{NOx}$ reduction goals of ERA. Current superalloys require high cooling air flows to keep them below their maximum allowable operating temperatures (up to about $80 \%$ of their melting temperature). CMC materials offer operating temperatures that are $200^{\circ}-300^{\circ} \mathrm{F}$ higher than for superalloys. The higher temperature capability and less component cooling requirements allow for a wider combustor design space so that it can be run more efficiently. Less cooling flow to the component allows for more air to be put into the combustion process. The higher temperature and improved combustion efficiency decreases the emissions of $\mathrm{CO}$ and NOx. The use of EBCs will increase the temperature capability of the $\mathrm{CMC}$ by an additional $300^{\circ} \mathrm{F}$ (for example, an increase from $2400^{\circ} \mathrm{F}$ to $2700^{\circ} \mathrm{F}$ ).

Within Phase I of the ERA program, the combustor liner task is focused on EBC development and $\mathrm{CMC} / \mathrm{EBC}$ characterization and durability tests. Tasks included CMC strength tests, coating development to address fretting due to integration of CMC to metal, EBC development, CMC and EBC recession studies and model development, and CMC film cooling hole evaluation and CFD modeling. The ultimate objective was to evaluate the possibility of a CMC combustor liner that has higher temperature capability with less cooling flow requirements in a scale approaching those required for $\mathrm{N}+2$ engines.

The $\mathrm{SiC} / \mathrm{SiC} \mathrm{CMC}$ material used for maturing the CMC combustor liner technologies was the HiPerComp ${ }^{\mathrm{TM}}$ Gen II material by GE Energy. The SiC fibers were Hi-Nicalon Type-S. The SiC matrix was manufactured by the prepreg melt infiltration method ${ }^{2}$. The composite fiber architectures were $0 \% 90^{\circ}$ and $+45^{\circ} /-45^{\circ}$. Samples from 2-D panels were used for CMC characterization and durability tests. Tensile creep tests were conducted on dog bone-shaped tensile coupons at temperatures of $2200^{\circ} \mathrm{F}$ and $2400^{\circ} \mathrm{F}$ at stresses of 10,15 , and 20 ksi. Fast fracture tests were conducted at $72^{\circ} \mathrm{F}$ and $2400^{\circ} \mathrm{F}$. 
To address CMC scale up issues, component fabrication challenges, and to evaluate performance in engine environments, $\mathrm{SiC} / \mathrm{SiC}$ combustor liner sub-components were fabricated. Two inner combustor liners with an inner diameter of 3.5" and two outer combustor liners with an inner diameter of 4.0" as shown in Figure 1a were fabricated. The length of the liners is about 17". One inner and outer liner set had a fiber layup of $0^{\circ} / 90^{\circ}$ while the other set had a fiber layup of $+45^{\circ} \% 5^{\circ}$. An as-fabricated outer CMC liner and an EBC coated CMC inner are shown in Figure 1b. The inner liners are machined to add film cooling holes and then the inner and outer liners are coated with EBCs. Figure 2a shows an uncoated CMC outer liner and a coated CMC inner liner partially inserted into the combustion section of the High Pressure Burner Rig. Figure 2b is another view in the outer and inner CMC liners with the combustor injector shown. The liner sets will be tested in NASA's High Pressure Burner Rig (HPBR). During ERA Phase I, one liner set will be tested for $50 \mathrm{hr}$ in the HPBR. Long duration durability tests will help evaluate the capabilities of the CMC/EBC system for combustor applications which would require about $3000 \mathrm{hr}$ of life at the maximum hot hour conditions.

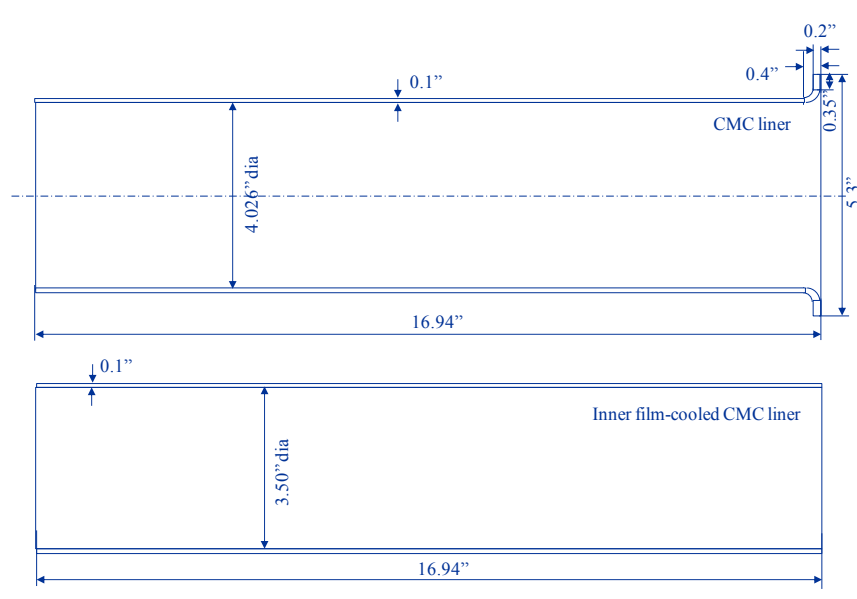

a)

b)
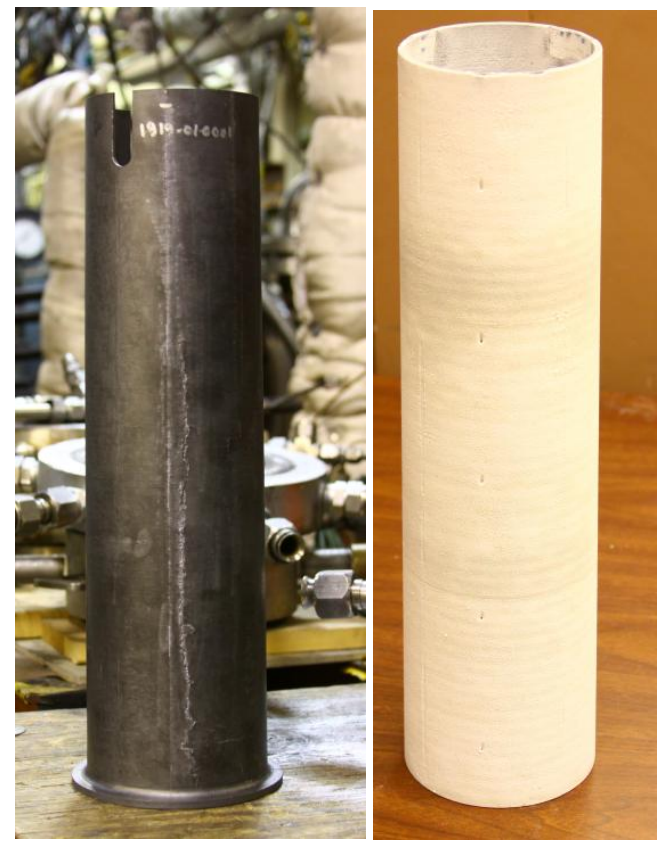

Figure 1. a) Dimensions of the outer (top) and inner (bottom) CMC liners and b) the fabricated CMC outer liner and the EBC coated CMC inner liner .

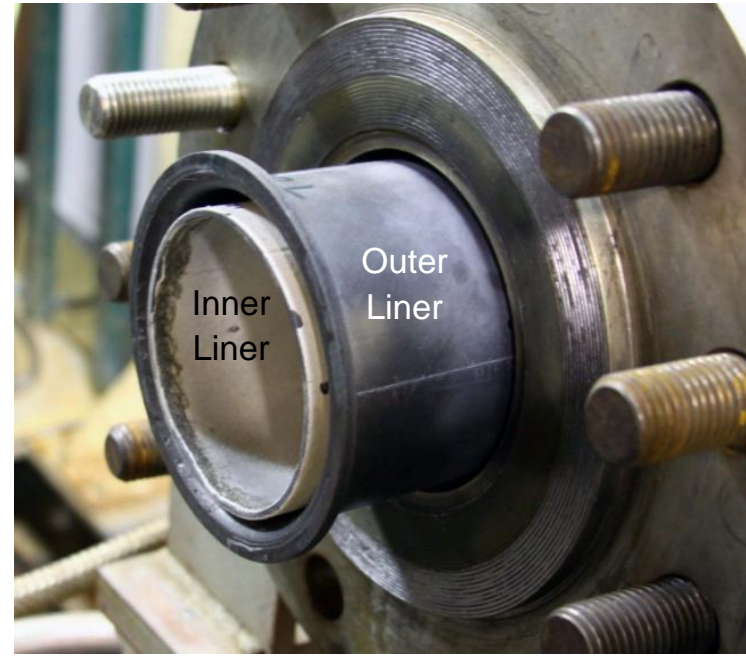

a)

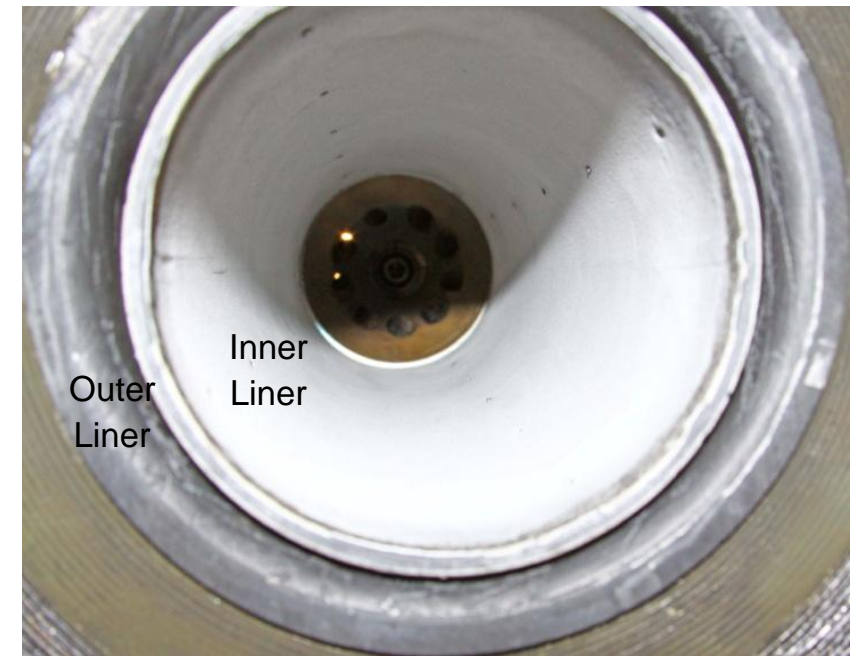

b)

Figure 2. a) An uncoated outer CMC liner and a coated inner CMC liner partially inserted into the HPBR and b) another view of the liners and the combustor injector. 


\section{B. CMC Vane}

Within Phase I of the ERA Project, the high pressure turbine vane task focused on the evaluation of processing methods suitable for producing complex vane shapes and the development of a suitable EBC and bond coat system. CMC and EBC materials were selected based on the projected requirements of a $2700^{\circ} \mathrm{F}$ coating surface temperature and an underlying $2400^{\circ} \mathrm{F}$ material temperature. These temperatures necessitated the development of not only an environmentally stable and erosion resistant EBC but also the development of a stable bond coat capable of long duration use at temperatures beyond the currently available silicon based bond coat systems.

Two different manufacturing approaches were evaluated within the CMC vane task. SiC fiber reinforced $\mathrm{SiC}$ matrix $(\mathrm{SiC} / \mathrm{SiC})$ composites were manufactured by the GE Energy prepreg melt infiltration (MI) process and by the Hyper-Therm chemical vapor infiltration (CVI) process (htcomposites.com). Both processing methods were based on 2D laminate architectures, utilizing Hi-Nicalon Type S fibers. The melt infiltration method used a $0^{\circ} / 90^{\circ}$ unidirectional tape layup while the CVI method incorporated five harness satin weave cloth as the reinforcement phase. The fiber volume varied from approximately $21 \%$ for the MI samples to approximately $35 \%$ for the CVI materials. Both methods were used to fabricate 6.0" x 6.0 " flat panels with a thickness of 0.060 " and a simplified airfoil configuration (Fig. 3). The simplified vane shapes were designed to incorporate some of the challenging processing features of the vane, such as the rib section, sharp trailing edge radius and varying wall thickness, but still allow for sectioning and testing of flat coupons. The objective was to make a direct comparison between the optimum properties which are typically measured with a flat panel and those found in the more challenging 3-D components. The goal was to assess both processes for suitability when used to manufacture a complex component and identify potential fabrication issues.

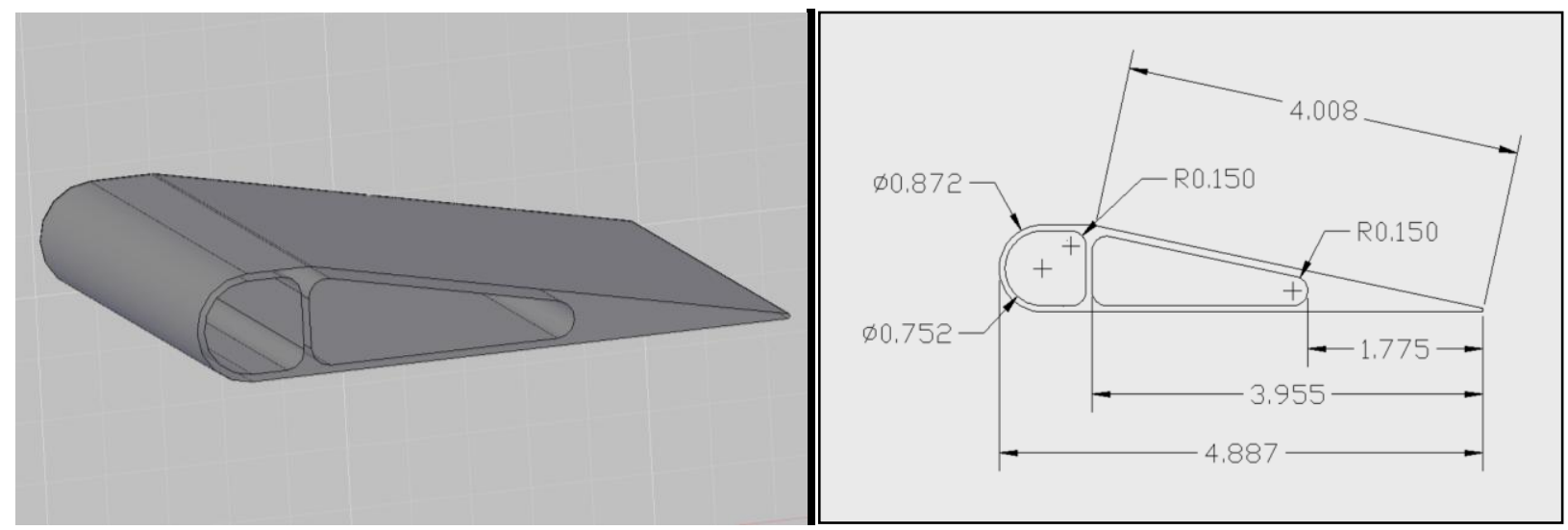

Figure 3. Schematic and dimensional drawing of simplified vane test article (all dimensions in inches).

Non-destructive evaluation (NDE) of all panels and vanes was conducted prior to sectioning and testing of the samples. Computed tomography (CT) scans revealed processing flaws in only the vanes. Scans of the flat panels revealed material of uniform density with almost no detectable flaws. CT scans showing the cross sectional views of both the MI and CVI vanes are shown Figure 4. These images are representative of the types of flaws found in all vanes. In general, the MI material had only isolated areas of porosity and slight variation in wall thickness in a few vanes. For the CVI material, density variations, pores in the filets and delaminations in the leading edge were detected in several samples.

Following NDE, all panels were sectioned for mechanical and thermal property testing while some of the vanes were sectioned (as seen in Fig. 5) and some were left intact for testing in the HPBR at NASA GRC. Initial testing indicated that both MI and CVI vanes showed losses in properties compared to their flat panel counterparts. The decrease in matrix density in CVI vane materials (as seen in Fig. 6) resulted in losses in matrix controlled properties, such as thermal conductivity (seen in Fig. 7) and bend strength (Figs 8 and 9). The lower fiber volumes in MI composites combined with ply joints within the bend samples led to flexural strength losses in MI vanes. 


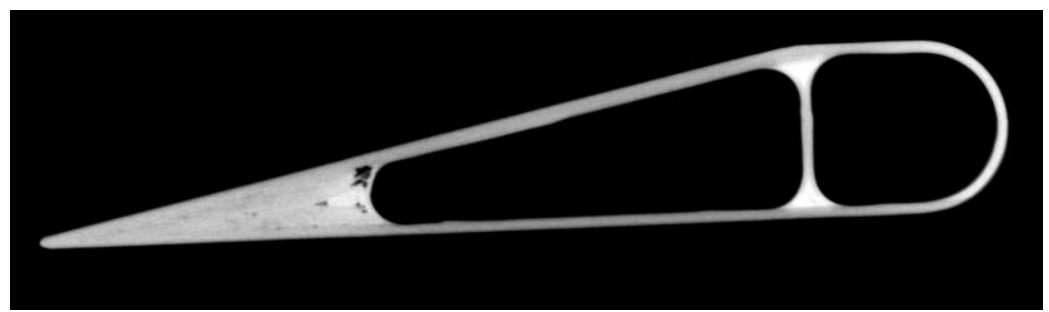

4a) CT scan of cross section of melt infiltration vane.

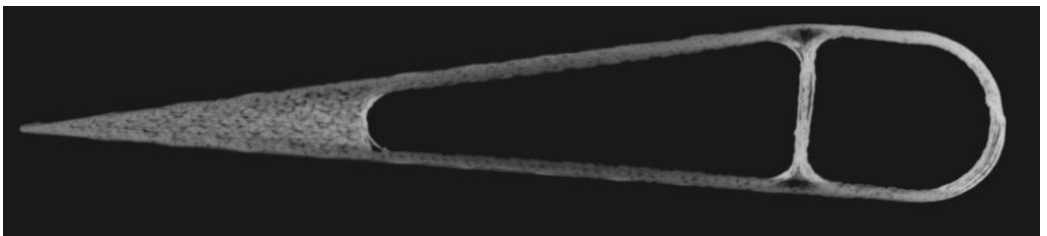

4b) CT scan of cross section of chemical vapor infiltration vane.
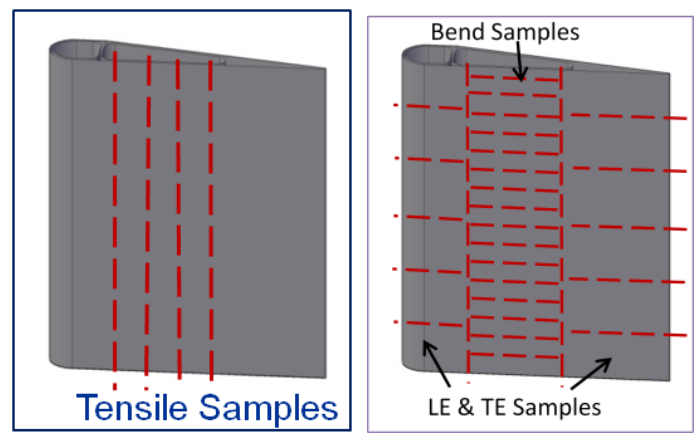

Figure 5. Schematic of samples machined from 3D vanes.

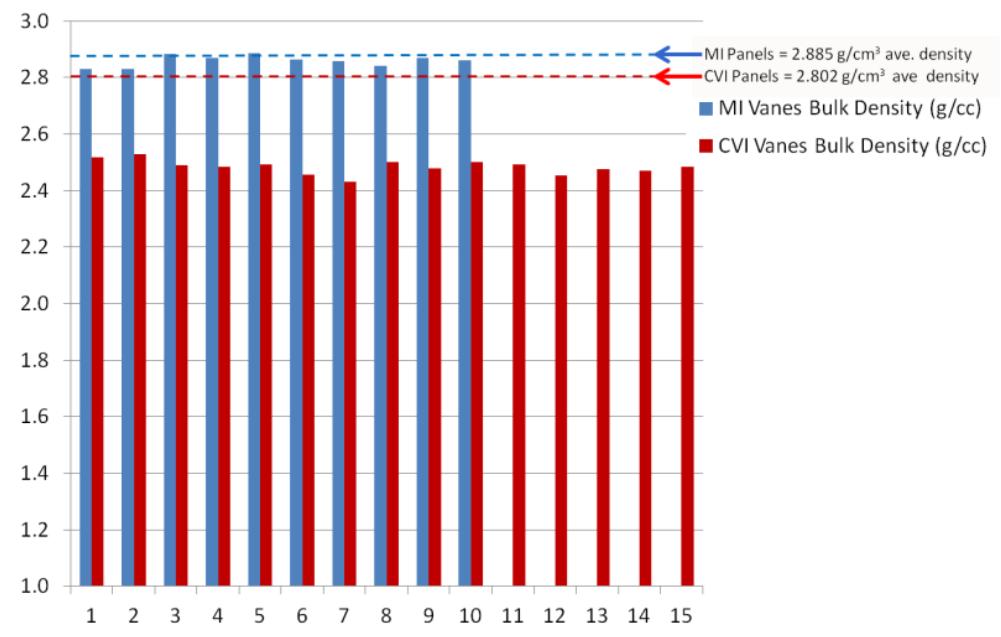

Figure 6. Densities of individual MI and CVI vanes compared to average densities of MI and CVI panels 


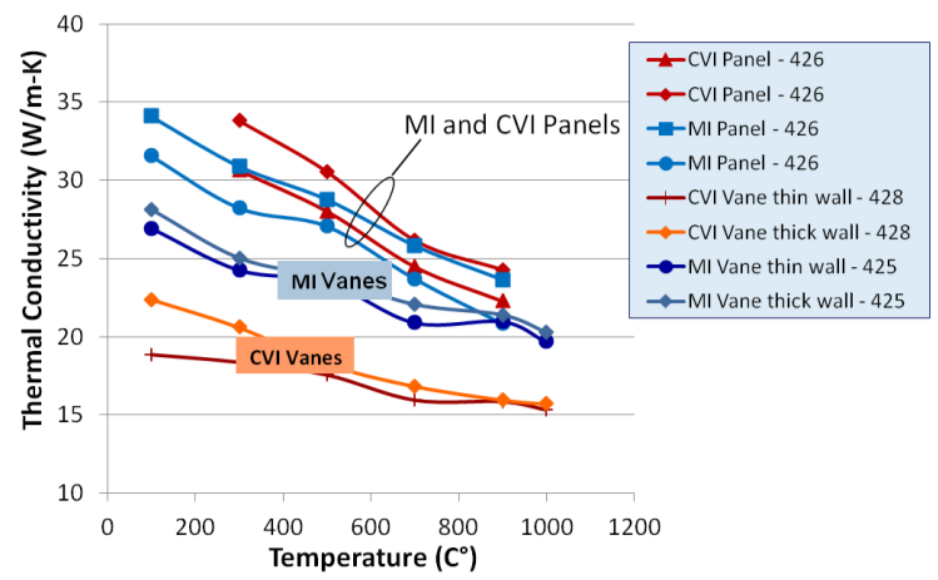

Figure 7. Thermal conductivity as a function of temperature of MI and CVI vanes and panels.

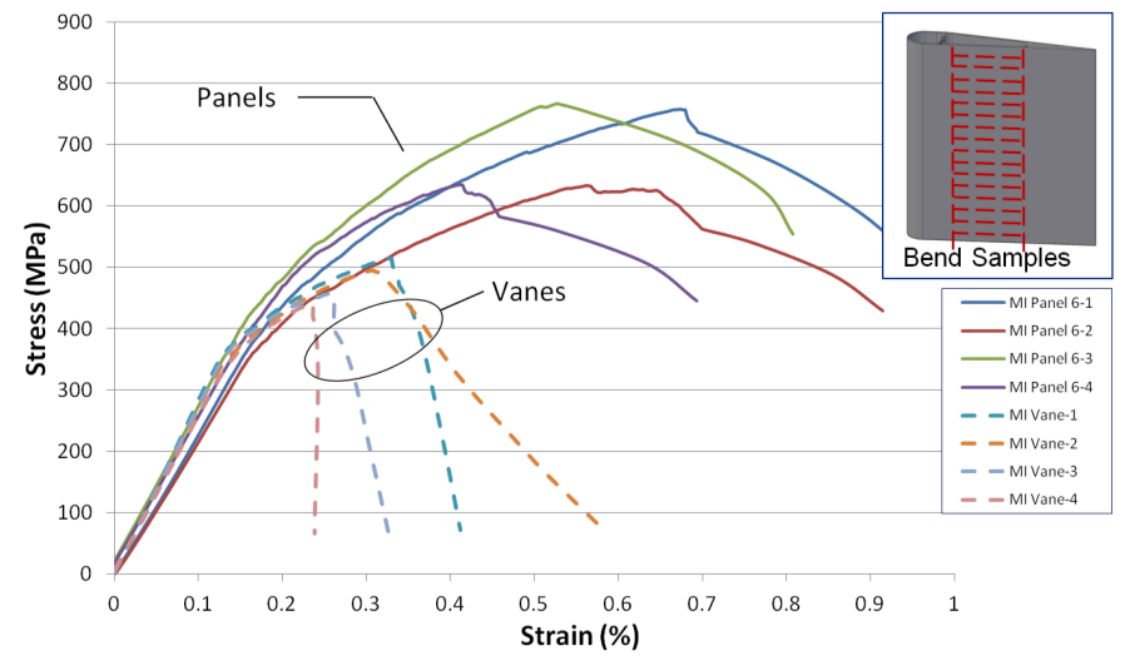

Figure 8. Room temperature bend strength of MI panels compared to MI vanes.

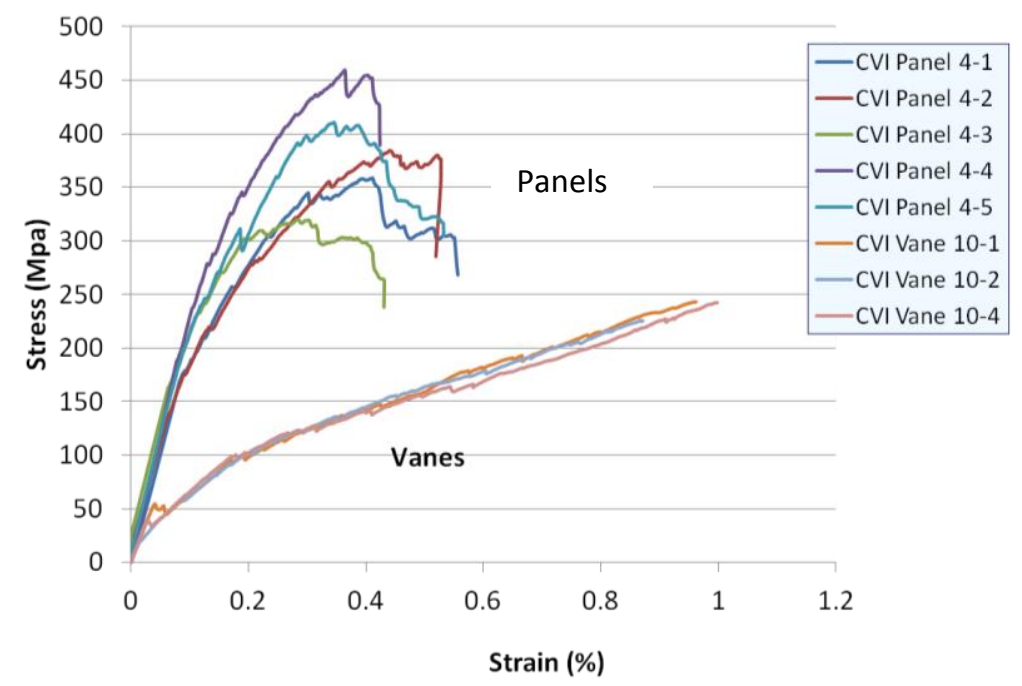

Figure 9. Room temperature bend strength of CVI panels compared to CVI vanes. 
From the mechanical and thermal test data, some of the needed improvements which were identified were higher proportional limit in CVI materials, improved strain capability in MI while maintaining proportional limit, and increased thermal conductivity in all materials. Necessary processing advancements which were identified were reduced porosity in CVI materials, uniform wall thickness in both MI and CVI samples, better control at ply joints for all materials, elimination of delaminations in CVI samples, and higher fiber volume in MI materials.

\section{EBC Development and Testing for SiC/SiC Combustor and Turbine Vane Components}

EBCs are generally considered prime reliant in order to fully realize the benefits of $\mathrm{SiC} / \mathrm{SiC}$ composites in the harsh combustion environment of a turbine engine. The development of advanced environmental barrier coatings under the NASA ERA Project is currently aimed at significantly improved EBC system temperature capability and stability for $\mathrm{SiC} / \mathrm{SiC}$ combustors and turbine vane components. The improved $\mathrm{EBC}$ systems are critical to the performance, life and durability of the hot-section $\mathrm{SiC} / \mathrm{SiC}$ components in the advanced engine systems.

Under the NASA ERA Project, combustor and turbine vane environmental barrier coatings at the TRLs of 4 to 5 are being developed. Efforts are focusing on the development of two different methods of coating application. Advanced plasma-sprayed, multi-layer, $3000^{\circ} \mathrm{F}\left(1650^{\circ} \mathrm{C}\right)$ capable $\mathrm{EBCs}$ are being evaluated for combustor applications. For the vane application, full electron beam - physical vapor deposition (EB-PVD) thin coatings (120$250 \mu \mathrm{m}$ thick) with $2400^{\circ} \mathrm{F}$ capability are being studied. One thousand $\mathrm{hr}$ durability will be demonstrated in simulated laboratory conditions in order to help meet the ERA Project goals.

The NASA ERA environmental barrier coatings have utilized innovative and state-of-the-art multicomponent hafnia/zirconia-rare earth oxide and silicate composite designs to ensure high temperature thermal and environmental stability and mechanical integrity. Advanced composition designs, processing developments and optimizations, and laboratory simulated component testing have been a major emphasis for developing the high TRL environmental barrier coating systems. The efforts have resulted in improved coating compositions for both combustors and turbine vanes. In addition, advanced hafnia-silicon 3-dimensional (3D) thin bond coats with initial $2600^{\circ} \mathrm{F}+\left(1426^{\circ} \mathrm{C}+\right)$ temperature capability have been demonstrated. The state-of-the-art Treplex Pro, Dense-Vertic Crack (DVC) plasma spray processing, hybrid plasma spray and EB-PVD, Directed Vapor EB-PVD processing are being and have been developed for processing NASA ERA advanced environmental barrier coating systems.

The demonstration of advanced EBCs and $\mathrm{SiC} / \mathrm{SiC}$ CMC component systems requires the development of testing techniques that can accurately evaluate the coating and CMC systems under simulated engine conditions. The NASA GRC high velocity and high pressure burner rig (shown in Figure 10) provides relevant heat flux conditions and surface temperature up to $2700-3000^{\circ} \mathrm{F}\left(1482-1650^{\circ} \mathrm{C}\right)$ to evaluate the coated $\mathrm{CMC}$ component systems. The EBC stabilities and $\mathrm{SiC} / \mathrm{SiC} \mathrm{CMC}$ baseline recession data have been studied and modeled for both combustor and turbine vane material systems (Figure 11).

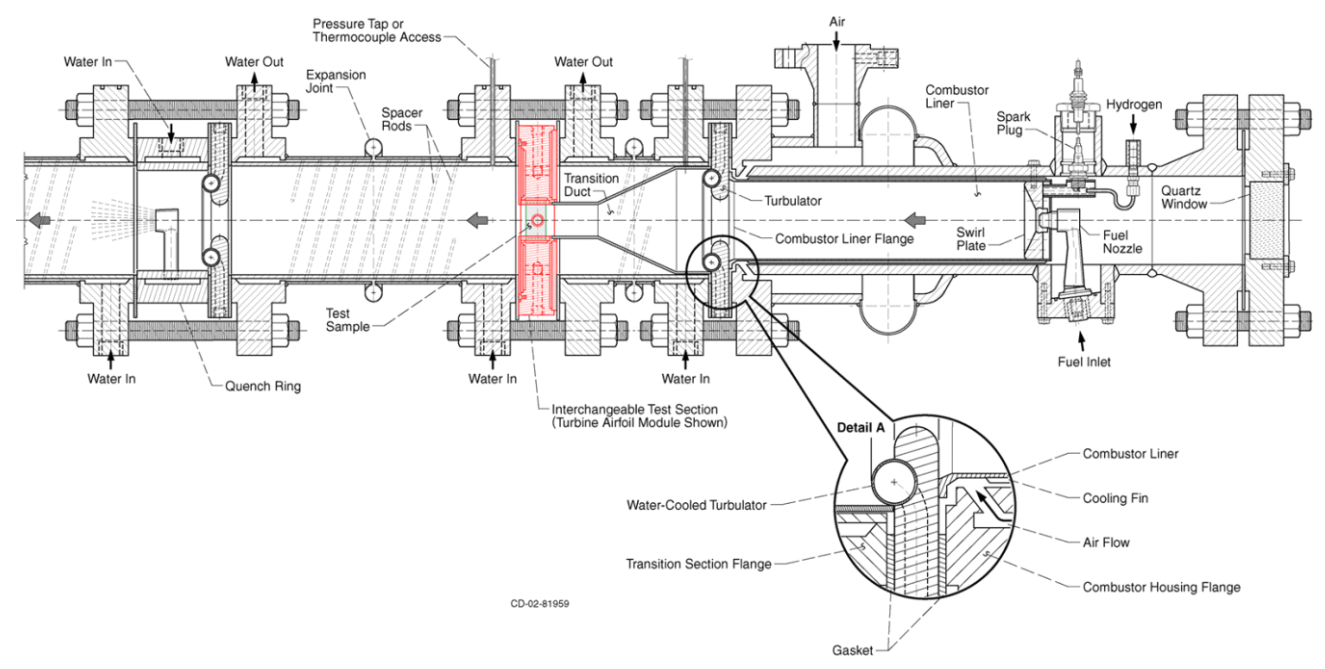

Figure 10. Schematic representation of the NASA High Pressure Burner Rig, capable of $3000^{\circ} \mathrm{F}\left(1650^{\circ} \mathrm{C}\right)$ testing temperature at $16 \mathrm{~atm}$. 
A unique steady-state $\mathrm{CO}_{2}$ laser (wavelength $10.6 \mu \mathrm{m}$ ) heat-flux test rig has been developed and used to determine the thermal conductivity and cyclic durability of material systems at high temperatures and under large thermal gradients across the environmental barrier coatings. To further simulate the high thermal gradients and heat fluxes of the turbine engine, a high-power $\mathrm{CO}_{2}$ laser heat-flux rig is used. The simulated combustion water-vapor environment, creep rupture and thermomechnical fatigue testing capabilities have also recently been incorporated into the laser heat-flux and burner rigs. Advanced component and EBCs have been extensively tested under various laboratory simulated engine environments, supporting the demonstration of initial long-term (1000 hr) coating durability under high heat flux and mechanical conditions, as shown in Figure 12.

a)

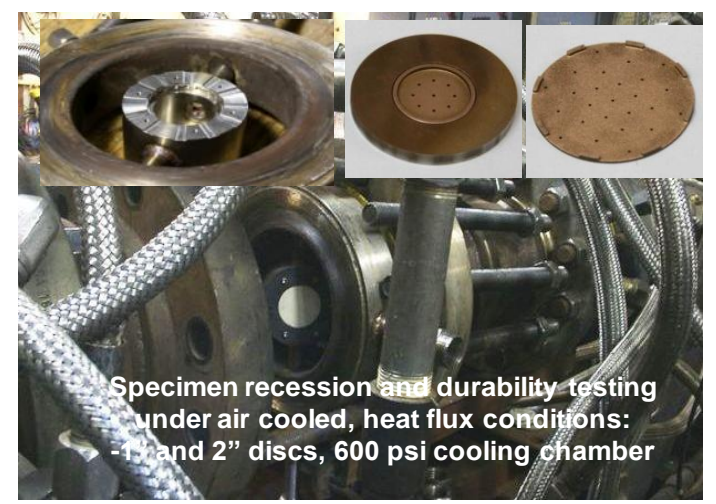

c)

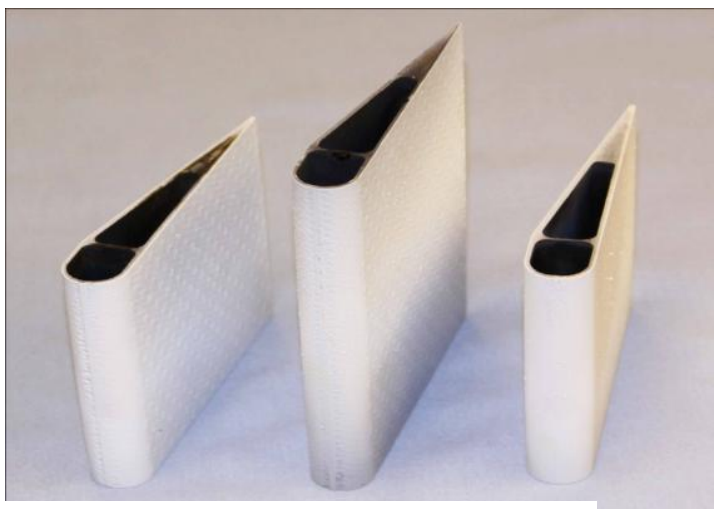

e)

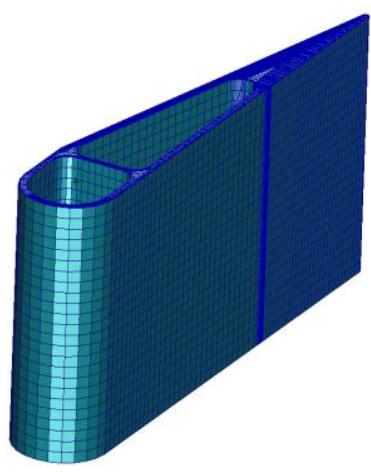

b)

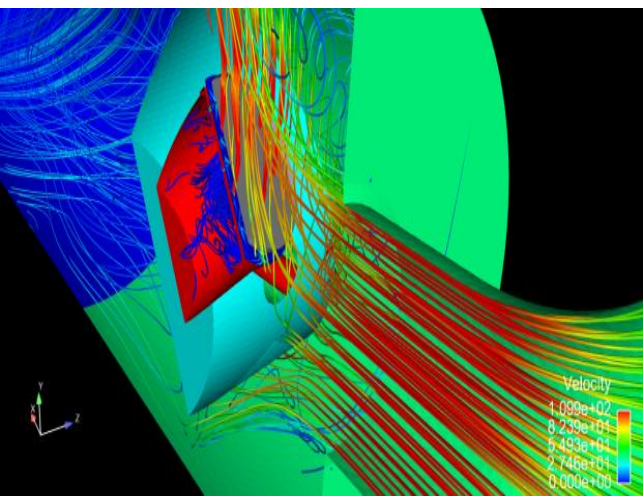

d)

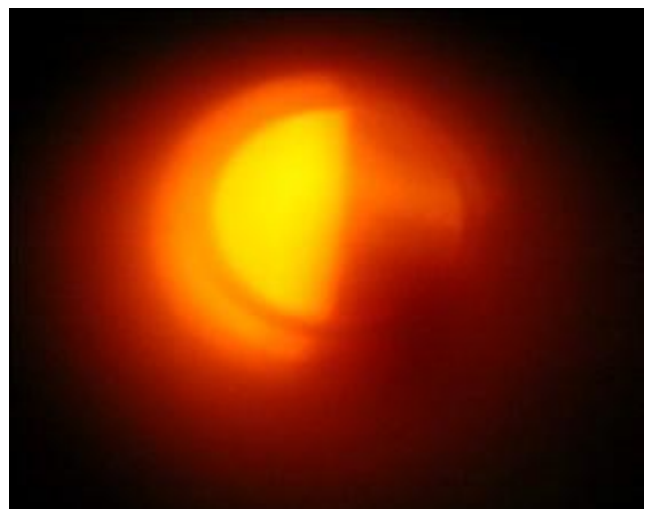

Figure 11a-e. NASA High Pressure Burner Rig testing and modeling. a) Coated and uncoated CMC film-cooled combustor liner sub-component testing and b) CFD modeling; c) advanced EBC coated $\mathrm{SiC} / \mathrm{SiC} \mathrm{CMC}$ vanes, d) initial testing and e) stress modeling. 

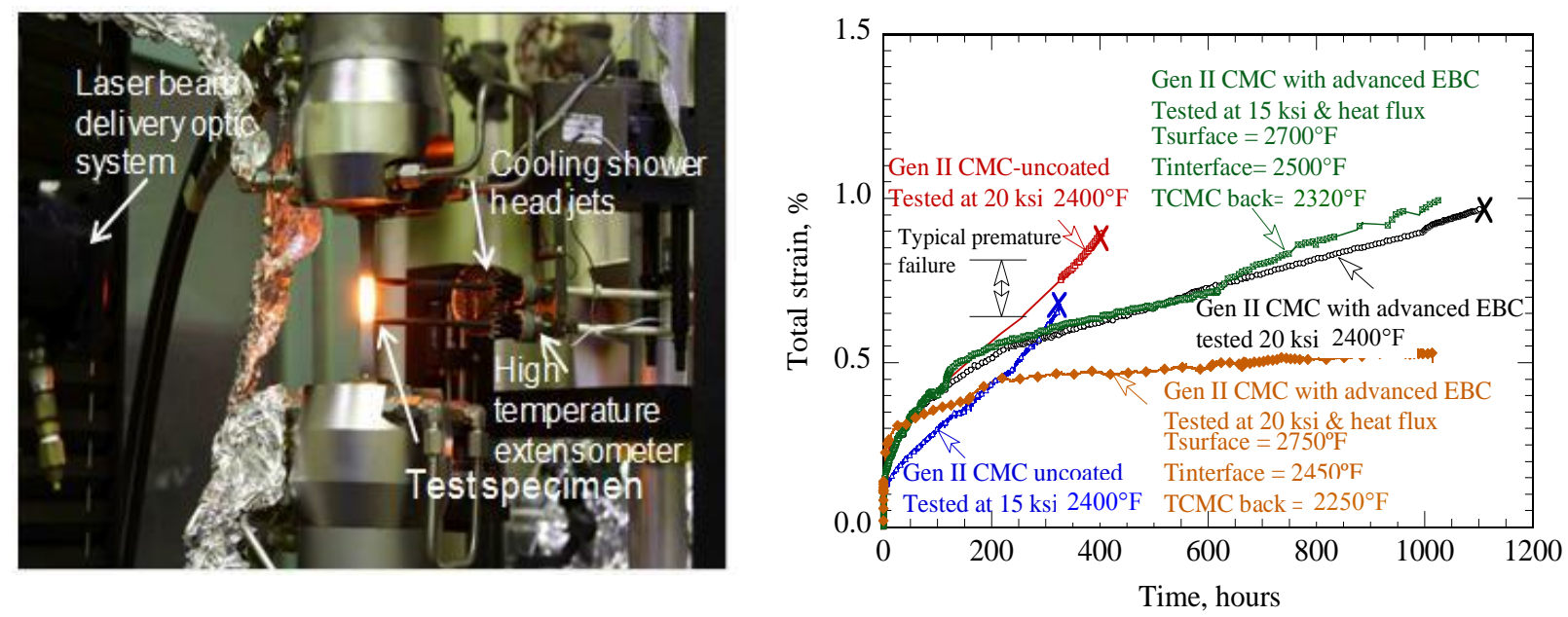

Figure 12. Laser high heat flux rig used for advanced EBC and subelement developments. EBC coated CMC specimens tested in simulated high heat flux and mechanical loading conditions, demonstrating $1000 \mathrm{hr}$ stressrupture durability at $15 \mathrm{ksi}(103.5 \mathrm{MPa})$ and $20 \mathrm{ksi}(138 \mathrm{MPa})$ stress levels.

Coated $\mathrm{SiC} / \mathrm{SiC} \mathrm{CMC}$ specimens and subelements with environmental barrier coatings have demonstrated $10-20 \mathrm{mg} / \mathrm{cm}^{2}-\mathrm{hr}$ recession stability in simulated laboratory High Pressure Burner Rig combustion environments, and $1000 \mathrm{hr}$ stress-rupture durability at $2700^{\circ} \mathrm{F}+$ high heat flux and up to $20 \mathrm{ksi}(138 \mathrm{MPa})$ mechanical stress conditions. The combustor and turbine vane environmental barrier coatings have also achieved 0.6 and $1.2 \mathrm{~W} / \mathrm{m}-\mathrm{K}$ thermal conductivity values, respectively, which are critical for meeting the CMC component design goals. Figure 13 shows downselected coating system meeting initial coating performance and durability goals. The continued coated component development and testing will be aimed at establishing the design database, component EBC processing optimization, and demonstration of the system durability in more complex and demanding test conditions.

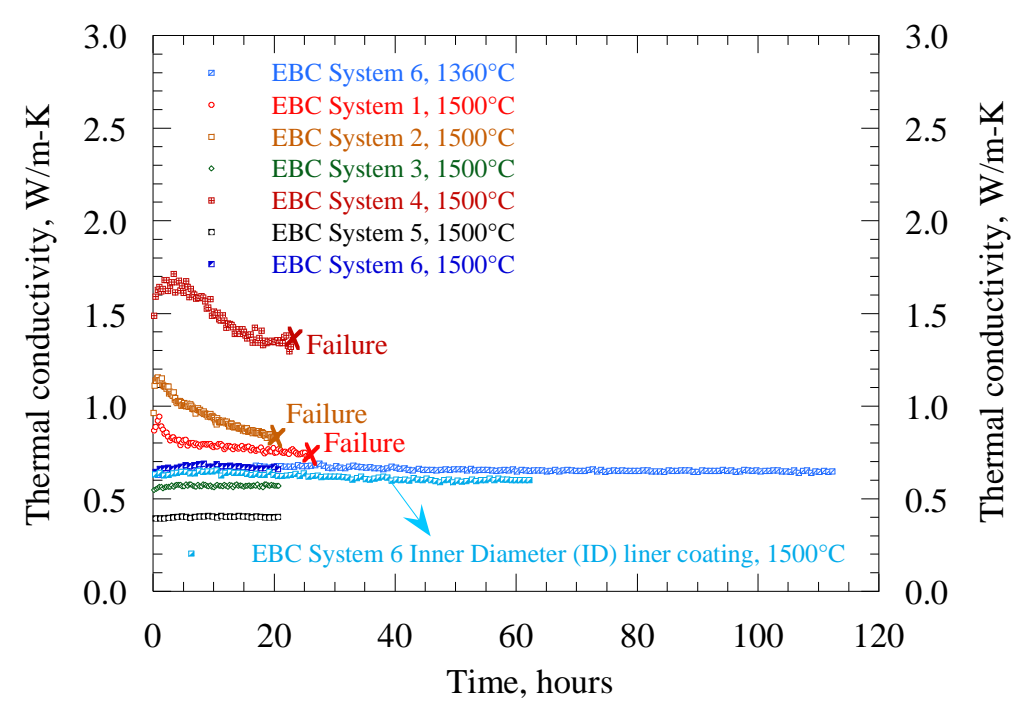

Figure 13. High heat flux thermal gradient and cyclic testing of combustor liner environmental barrier coatings. The down selected initial combustor EBC system 6 demonstrated $2700^{\circ} \mathrm{F}$ cyclic durability and low thermal conductivity. 


\section{Development of Oxide/oxide CMC Exhaust Mixer Nozzle Technology:}

NASA Glenn Research Center (GRC) teamed with Rolls-Royce LibertyWorks ${ }^{\circledR}$ (RRLW) and ATK COI Ceramics, Inc. (COIC) on oxide/oxide CMC exhaust mixer nozzle development for subsonic jet engines capable of operating with increased performance and reduced noise. The collaboration was funded by the NASA ERA project and by significant industry cost-sharing, with the intent to advance the technology to full scale engine testing and thus, maturation to TRL 6 . This development and demonstration task was pursued largely because efforts to improve fuel efficiency have driven aircraft engine operating temperatures higher, and traditional titanium exhaust structures will be unable to handle the increased temperatures and still deliver full life (requirement of 85,000 hrs) in future engines. Thus, the use of CMC exhaust nozzles to improve component durability and avoid weight increases associated with switching to heavier metallic alloys such as Inconel is being evaluated by companies such as The Boeing Company, Snecma, and RRLW.

Turbofan engines utilized on both regional transport and business jets often feature an exhaust mixer, where the bypass (cold) air is mixed with the core (hot) exhaust gases, before exhausting to atmospheric pressure through a common propelling nozzle (Figure 14. (a)). The mixer reduces the average velocity of the exhaust. In terms of benefits of the mixer nozzle, there is a reduction in the amount of noise produced, the temperature of the exhaust plume is reduced, and a small thrust gain occurs, which improves specific fuel consumption. CMC exhaust mixer nozzles can also offer an advantage if they are able to maintain their shape during operation, and avoid the performance-degrading shape-distortion that metallic nozzles can exhibit. The mixer of interest in our ERA effort is a forced flow mixer nozzle (Figure 14. (b)), having hot and cold chutes that are radially-intertwined, which forces the two streams to mix. Forced mixers can have a high mixing efficiency (which is basically a comparison of the actual thrust gain (due to mixing) to that of the ideal case). Snecma has successfully demonstrated a CMC mixer nozzle on a CFM56-5C engine (ground-based test). They performed 700 endurance cycles, and observed a weight reduction of $45 \mathrm{lbs}$. via incorporation of the CMC mixer ${ }^{3}$. That is viewed as the current SOA in terms of CMC mixers. The NASA-led ERA CMC mixer nozzle effort is focused on a different composite material system, an oxide/oxide CMC, which uses a relatively inexpensive fiber reinforcement. This CMC does not require a protective surface coating to prevent oxidation of the constituents.

Following an in-depth design effort based upon operating conditions a mixer nozzle would experience in a turbofan engine, a subscale oxide fiber/oxide matrix composite mixer nozzle was fabricated by COIC, and delivered to GRC (Figure 15). The dimensions of this hardware were dictated by the rigs that the team had selected for subscale component testing. Following nondestructive evaluation (NDE) at GRC using x-ray computed radiography, the nozzle assembly (consisting of the CMC mixer and center body, mounted on metallic attachment rings) was sent to ASE FluiDyne in Plymouth, MN, to assess its aero-performance in the Channel 11 Hot/Cold Dual Stream Static Nozzle Test Facility. Next, acoustic performance was examined at GRC in the Aero-Acoustic Propulsion Laboratory. Various combinations of temperature and pressure ratios were evaluated in the testing in both facilities. NDE performed following the completion of both types of testing did not detect any damage resulting from those tests. Overall, the demonstration of COIC's ability to fabricate a fairly-complicated subscale component and the validation of the performance benefits during successful rig tests to achieve TRL 4 encouraged the NASA/RRLW/COIC team to move forward with plans to build full-scale oxide/oxide CMC mixer nozzles.

The objective of the follow-on effort is to demonstrate the fabrication and durability (via vibration testing) of full scale CMC mixer nozzles and achieve TRL 5. This would enable a follow-on engine test to validate the scalability of the performance benefits such as reduced fuel consumption and noise (TRL 6). 

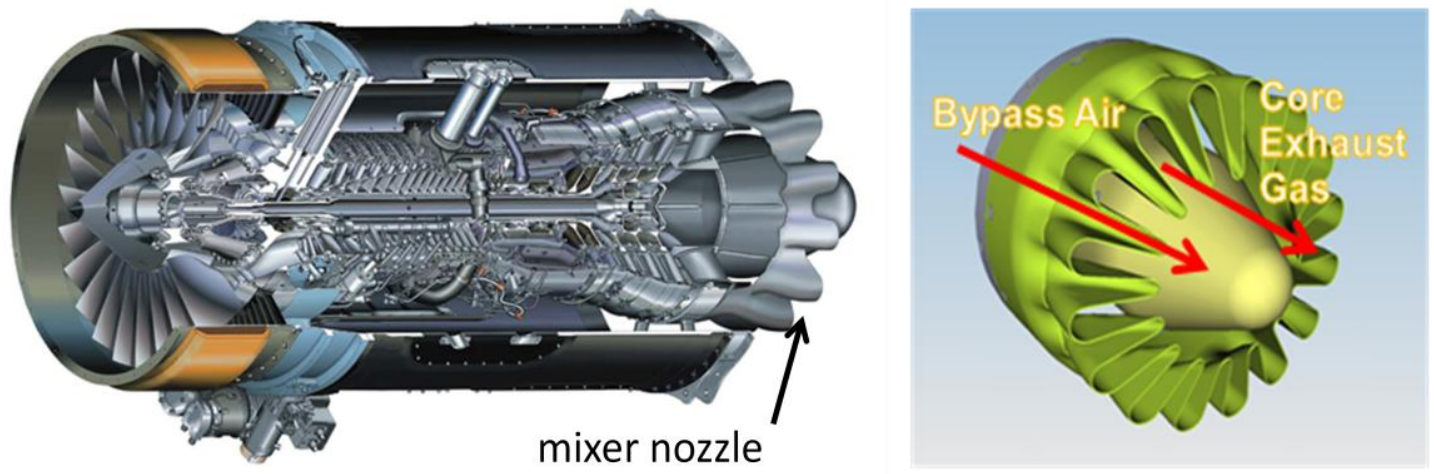

Figure 14. a) Example of an aircraft engine that has an exhaust mixer nozzle (AE3007); b) forced flow mixer nozzle.

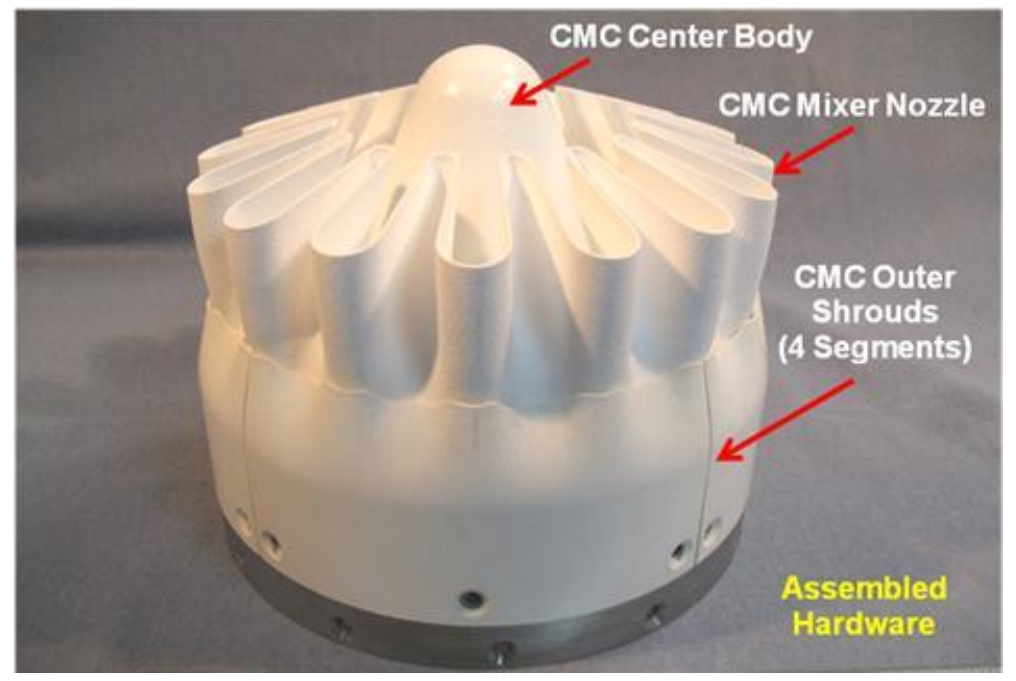

Figure 15. Subscale oxide/oxide CMC mixer nozzle assembly, including metallic attachment rings.

\section{Conclusions}

Significant progress continues to be made in developing ceramic matrix composite components for aircraft engine applications in order to meet the ERA performance goals for reductions in emissions and fuel burn. The manufacturability of the complex components is being demonstrated and their performance and durability are being evaluated under simulated engine operating conditions. Deficiencies in manufacturing and performance will continue to be assessed and reported. The CMC combustor (w/EBC) is aimed at providing $2700^{\circ} \mathrm{F}$ temperature capability with less component cooling requirements to allow for more efficient combustion and reductions in NOx emissions. The CMC vane (w/EBC) should have temperature capability to $2700^{\circ} \mathrm{F}$ and allow for reduced fuel burn. The CMC mixer nozzle should offer reduced weight and improved mixing efficiency to provide reduced fuel burn.

\section{Acknowledgements}

This work was supported by the NASA Environmentally Responsible Aviation (ERA) Project within the Integrated Systems Research Program (ISRP).

\section{References}

${ }^{1}$ National Aeronautics Research and Development Plan, Executive Office of the President, National Science and Technology Council, Washington, D.C. 20502, February 2, 2010.

${ }^{2}$ Corman, G.S., and Luthra, K.L., "Silicon Melt Infiltrated Ceramic Composites (HiPerCompTM)," in Handbook of Ceramics and Glasses, ed. N. Bansal, Kluwer Academic Publishers, Boston, 2005, pp. 99-115.

${ }^{3}$ Eury, S., "The next generation engines: Major axes for new technologies," presented at The $8^{\text {th }}$ International Symposium on Experimental and Computational Aerothermodynamics of Internal Flows, July 2-5, 2007, Lyon, France. 